\title{
Fonts literàries clàssiques sobre el vidre antic
}

\author{
Teresa Carreras I Rossell * \\ Pere VILlalba I Varineda **
}

En aquesta publicació en homenatge al Professor Eduard Ripoll $i$ Perelló no podia faltar un estudi sobre el vidre antic, ja que ell va saber, al seu temps, conhortar i impulsar aquest tipus d'investigació a l'àmbit de les recerques arqueològiques a Catalunya. Amb el desig també que aquest homenatge contribueixi a la confrontació de la ciència històrica entre els diversos col-laboradors, el nostre estudi, una vegada més, vol presentar una mostra simple d'un estudi global on conflueixen les fonts arqueològiques $i$ les fonts literàries clàssiques, idea i mètode gens llunyans al tarannà científic del nostre homenatjat.

L'estudi, doncs, que presentem, es proposa abastar un tema molt clar i un objectiu molt precís: complementar, des del punt de vista de la Filologia clàssica, les dades aportades per l'Arqueologia. Al mateix temps, l'abundància de fonts clàssiques sobre el vidre antic fa pensar en una realitat veritablement viscuda a la meitat occidental de la Mediterrània, de manera que, sense un comerç pròsper, la terminologia clàssica, tan sensible a les novetats $i$ al progrés, no hagués recolzat, amb una riquesa verbal sense parió, les transaccions comercials. Primer punt, doncs, a fer notar, que l'abundància de termes per expressar el vidre $i$ els diversos objectes fets de vidre no té comparació amb els termes creats per a expressar altres manufacturacions. Només en les fonts clàssiques fins al segle IV-V, el grec coneixia cinc "paraules genèriques" per anomenar el vidre, $i$ el llatí, quatre, tres de les quals són adaptacions de les parau-

* Museu Arqueològic de Barcelona.

** Universitat Autònoma de Barcelona. 
les gregues, i una, el uitrum, és d'encuny llatí, amb tant d'èxit, que és a la base de la paraula que fem servir en la nostra llengua i de la majoria de les llengües romàniques. És més, hom ha estudiat més de 80 noms de peces vitries, tan grecs com llatins, alguns dels quals amb aportacions òptimes quant a la forma o a alguna peculiaritat de la peça. El seu nombre tan abundós no permet, però, que puguin ésser tractats aquí.

A la vista de la Bibliografia, el vidre desperta l'atenció ja al segle XVIII, quan George Agricola publica dues obres, la De Re Metallica i la De Natura Fossilium, a Basilea (1657). Un llarg silenci sobre el nostre tema omple el segle XVIII, però el segle XIX veurà aparèixer una varietat veritablement sorprenent d'obres i d'estudis interessats pel tema del vidre, fruit lògic de l'eclosió de la "Altertumswissenschaft" que caracteritza la investigació del segle $x \mid x, i$ també de les espectaculars recerques arqueològiques. Al segle $x x$, apareixen les sintesis i les sistematitzacions, i, per citar només les fonamentals, cal esmentar la monumental obra d'Anton Kissa, Das Glass im Altertume ( 3 vols., Leipzig 1908), pel que fa a una visió arqueològica del tema, i el minuciós estudi i alhora tesi doctoral de Mary Luella Trowbridge, Philological Studies in Ancient Glass (Urbana 1930), des d'una perspectiva filològica, com ja indica el mateix títol, totes dues precedides $i$ seguides per una munió d'obres que fonamentalment cobreixen l'àmbit de les excavacions, el de l'estudi de tècniques $i$ el de les classificacions i taules paradigmàtiques.

Així les coses, és evident que es fa difícil de fer una aportació en el camp de l'estudi del vidre bufat, en el període dels quatre primers segles de l'Era, sense quedar deutor als estudiosos que han precedit. Això no obstant, el nostre propòsit serà el de sintetitzar alguns dels punts de vista ja publicats, i alhora aclarir alguna ombra per petita que sigui, segons aquell principi que entén la ciència com quelcom sempre en progrés als ulls de l'especialista. Les col-leccions de vidres guardades als Museus parlen d'anàlisis químiques, de sistemes de producció, de materials emprats, de varietats de formes i de la importància del seu comerç. La Filologia, doncs, ha de complementar i completar, si cal, aquesta història de dades més o menys fredes amb la història deixada pels escriptors grecs i llatins sobre els orígens de la fabricació i de la troballa de la matèria primera, sobre el seu ús, sobre la manera de fabricar un forn, sobre la varietat dels colors emprats, sobre la seva tipologia $i$, també, on foren fabricats. Tot això, envoltat del misteri científic que tota història humana amaga dins seu.

Així, doncs, la nostra aportació es limitarà a una nova lectura de la terminologia clàssica tal com apareix a les fonts escrites, i a una indicació 
del plurivalent ús i de les aplicacions del vidre en la mateixa Antiguitat greco-romana.

\section{LA TERMINOLOGIA GREGO-LATINA}

La primera paraula testimoniada és kýanos. El conjunt de l'obra homèrica és la font principal quant a aplicacions del Kýanos: les parets de bronce del palau d'Alcínous eren coronades per un fris fet d'aquest material $(\mathrm{Od} .7,87)$; Néstor tenia una taula amb els peus del mateix material (II. 11, 629); l'armadura i l'escut d'Agamèmnon era adornats amb tres dragons fets amb aquest material (II. 11, 24 ss.); el cèlebre escut d'Aquil.les presenta dibuixos fets també amb aquest material (II. 18, 564; Hes. Schol. 143). En aquests punts, el Kýanos representa el color negre $o$, més aviat, un color fosc. L'adjectiu derivat d'aquesta paraula és aplicat preferentment per descriure el color fosc dels cabells, dels ulls, dels núvols, d'un exèrcit en ordre de batalla, de les proes de les naus, de la terra i dels vestits de la deessa marina Tetis (cf. M. L. Trowbridge, o. c., 11-12).

Teofrast (s. IV/III a.C.) és el primer a parlar de la naturalesa del “Kýanos". El kýanos, diu, por ésser natural i artificial, i n'hi ha a Egipte, a Escitia i a Xipre. El d'Egipte és artificial, és a dir, prové de fondre un material natural. N'hi ha de color fosc (Egipte) i de color més clar (Escitia). Els fabricants de pigments aconseguien quatre colors: els primers eren més clars, perquè provenien de les parts més exteriors, i els altres eren més foscos, perquè els treien de les parts més denses (De lapid. 55). El color del safir s'assembla al més fosc dels kyanoî (Trowbridge, 0. c. 31-37). Es troba junt amb metalls, amb tocs de color d'or, la qual cosa li dóna una certa brillantor (Trowbridge, o. c. 51 i 39).

Dioscòrides (s. I d.C.) parla només del kýanos de Xipre $(5,106)$. Plini (s. I d.C.) diu només que era preferible el caeruleum de Xipre (ct. Nat. Hist. 33, 161; 37, 119).

Les interpretacions posteriors d'aquestes fonts literàries identifiquen el kýanos natural d'Escitia amb el lapislàtzuli i amb el seu color; el caeruleum o el kýanos de Xipre, amb l'atzurita; el kýanos artificial d'Egipte, amb una pasta de vidre. El kýanos dels palaus homèrics era l'artificial pasta de vidre, de color blau, tal com ho confirmà l'arqueologia de Tirint, realitzada per Schliemann. 
En conclusió, el terme kýanos significà, malgrat la divergència quant al color entre els diversos comentaristes, la pasta de vidre, per la seva semblança als minerals naturals. Quan el vidre féu la seva aparició, es creà un terme nou, ja que provenia d'una substància diferent.

Una segona expressió apareix en el món grec que fa pensar en la presència d'uns nous elements mercantils: es tracta de la lithos chytê, és a dir, la "pedra fosa". Heròdot (s. $\vee$ a.C.; a 2, 69) conta que, a Tebes $i$ al llac Moeris, el poble venerava uns cocodrils que adornaven amb arracades d'or i de "pedra fosa". També el testimoni de Plató (s. V-IV a.C.; Tim. 61B) diferencia entre el hýalos y el lithos chytê. Això no obstant, l'aspecte més interessant que gira entorn d'aquesta expressió del vidre és el del seu comerç. Així, el Periplus del segle Iv a.C., atribuit a Escilax (s. vi a.C.), descriu els fenicis com a comerciants de la "pedra egipcia" amb els africans occidentals (112, Müller, Geog. Gr. Min. I, 1855). El Periplus maris Erythraei (s. I-Il d.C.) descriu els egipcis exportant als berebers moltes menes de Lithía hyalê fetes a Diòspolis (6, ed. de Fabricius, 1883).

De fet, en la literatura no primerenca, fou usat primer el terme líthos chytê, i després, el de "hýalos". Es pot suposar que el terme lithos chytê significava, més aviat, objectes petits, i, posteriorment, hýalos arribà a assimilar aquesta significació, que uni al seu significat específic.

El tercer terme grec per significar el vidre transparent fou l'esmentat hýalos, originat d'una arrel que significaria "ploure", el seu adjectiu significaria "mullat", és a dir, "brillant", i com a substantiu, "gota-de-pluja". Altres filòlegs el relacionen amb el terme grec que significa «sal», o el consideren un terme estranger 0 en relació amb els coptes d'Egipte, i d'altres el troben emparentat amb el uitrum llatí, és a dir, de l'arrel sualo-, "pedra transparent" (cf. M. L. Towbridge, o. c., 22-23). Hyalos és usat sovint en relació al tractament dels morts a Egipte: es vessava hýalos sobre el mort, o es tapava el sarcòfag amb una lámina de hýalos que permetia de veure'l sense notar-ne la pudor. És molt possible que no es tracti de vidre, sinó més aviat d'una substància transparent, una mena de vernis o laca. En canvi, hýalos significa "vidre» en Aristòfanes (s. $v$ a.C.; Nub. 768) i en Plató (s. V-IV a.C.; Tim. 61B), i la seva peculiaritat era la seva transparència, la qual cosa donà peu a comparacions amb altres coses transparents, fins $i$ tot per indicar les qualitats morals d'una persona. Aquesta paraula ha estat relacionada també amb êlektros, 
"ambre", amb logoúrion, també "ambre", i amb sualiternicum, el nom esciti de l'àmbre segons Plini (Nat. Hist. 37, 33), tot relacionant-la amb l'arrel sualo- que hem esmentat més amunt. En conclusió, es pot dir que hýalos que ha significat normalment "vidre", però que tambè ha estat aplicat a substàncies transparents, sigui quina sigui llur naturalesa. Aquest terme fou transliterat pels romans en hyalus, usat tan sovint com uitrum, però limitat a obres poètiques i científiques. Això no obstant, en les obres on apareix no significa només "vidre", sinó "vidre verd", i és aplicat sovint a l'aigua en atenció a la transparència.

Associat a aquesta paraula hi ha un altre terme, krýstallos, és a dir, "gel», "aigua congelada". Apareix usat pels filòsofs en relació al cel, i pels físics, en relació al cristal.lí de l'ull. Encara que Hesiqui (s. $\vee$ d.C.) defineixi krýstallos com una "mena de vidre", els grecs a vegades anomenaven el vidre krýstallos, usat en objectes de regal i per contenir alguna cosa. Pausànias (s. II d.C.; 8, 18,5) parla de «vidre, cristall i mórria i d'alguna altra cosa feta de pedra', trencadissos. Possiblement entengui per cristall un producte artificial. La transliteració llatina és chrystallus. Plini el distingeix del vidre, quan escriu: "les copes de vidre han aconseguit una gran semblança a les copes (metàl.liques), però, encara que hagin augmentat el seu preu d'una manera prodigiosa, no han fet minvar el del cristall» (Nat. Hist. 37, 23 ss.). Plini també menciona un vidre fet a partir del cristall, i a vegades fa pensar que els vasos de cristall que ell comenta poden ésser vasos de vidre.

El cinquè mot grec relacionable amb el vidre és mórria, usat només per Pausànias, com ja hem vist al paràgraf anterior, i al Periplus maris Erythraei esmentat més amunt. Els romans el transcribiren per murra, murrha, myrra, myrrha, sense deixar la posibilitat a esbrinar-ne el seu origen ni el seu significat. En les dues fonts gregues, sembla que mórria sigui un producte artificial. En la literatura llatina apareix sovint l'expressió uasa murrina, però pocs autors en suggereixen la seva naturalesa. Properci (s. I a.C.; 4, 5, 26) és el primer a parlar de "copes murrines cuites en els forns dels parts". Plini és la font més rica en dades: les murrines vénen de la Pàrtia, les millors són de la Carmània, no són gaire grans, són primes com les copes normals, no tenen gaire brillantor, reflecteixen els colors de l'iris i tenen una certa aroma (Nat. Hist. 1, 37). Més endavant indica que la introducció d'aquests vasos és deguda a Pompeu, que el seu preu és elevadíssim, i que és objecte de competició entre els emperadors i poderosos (o. c. 37, 18-20). Amb tot, no és possible de saber què entén Plini per murrina.

Davant d'aquest panorama, hom pot concloure que els escriptors grecs i llatins no tenien gaire familiaritat amb aquesta mena de vasos, 
que consideren objectes de luxe. Per a Kisa no són res més que vasos de vidre, és a dir, uns vasos de vidre artificial anomenats millefiori o "vidre-mosaic « (cf. o. c., 2, 551 ss.; també Daremberg-Saglio 5, 941). Kisa, però, no és l'unica opinió, i moltes veus s'alçaren en contra (cf. M. L. Trowbridge, o.c. 93-94).

El terme llatí que fruí de més fortuna és uitrum. D'etimologia incerta, apareix per primera vegada en Lucreci (De rerum natura, 4,145 ) i en Ciceró (Pro Rabir. Post. 14, 40) amb el significat de "vidre". Isidor (s. VIVII) dirà que el nom de uitrum respon a la qualitat transparent que té. En general se l'ha identificat amb l'arrel *uid-, és a dir, "veure", la qual cosa seria interpretada com el material a través del qual hom pot veure-hi. Altres lexicògrafs el relacionen amb l'etimologia de l'aire, de l'aigua, del color verd, de la fragil.litat i del color blanc, però no han reeixit. Les seves qualitats bàsiques, com són la lluor i la brillantor, la transparència, la fragil.litat, la perillositat quan és trencat i la seva mal-leabilitat, han fet possible que se'l compari amb una gran diversitat de coses, tant materials com de caràcter intel-lectual. Amb tot, la qualitat predominant és la transparència. Segons que sembla, els romans entenien per uitrum el material que designava, amb més o menys relació amb les formes que pogués tenir. Aquesta paraula ha produit una quantitat considerable de derivats terminològics, tant de substantius com d'adjectius, la qual cosa és una prova més de la seva imposició com a terme per indicar tot allò que és fet amb pasta de vidre o similar (cf. M. L. Trowbridge, o. c. 6578). La paraula "uitrum» és també la que ha perdurat en les llengües romàniques amb els seus derivats.

\section{ÚS I APLICACIONS DEL VIDRE}

\section{En l'art}

Cronològicament, el vidre ha estat usat en els elements decoratius de l'arquitectura, en els objectes d'adorn personal, en les peces que constitueixen la vaixella d'una casa, i, posteriorment, per fer làmines primes i transparents emprades sobretot en les finestres. En conseqüència, a partir d'aquest moment usarem el nom "vidre» per indicar tot allò que, d'una manera 0 altra, està relacionat amb la pasta de vidre o amb el vidre bufat. 
En arquitectura, el vidre és aplicat a les parets, als terres $i$ a les columnes. Les fonts literàries així ho esmenten, però són relativament parques a precisar-ne més detalls, mentre que la font arqueològica revela moltes més coses. L'arqueologia ha testimoniat la presència del vidre aplicat a fets arquitectònics, a Egipte, a les ruines de Ninive i Babilònia i en la faiança. Els cretencs també tenien els seus centres de faiança, per influència egipcia. Més amunt, ja hem esmentat l'aplicació del vidre als palaus homèrics. Una aplicació que no podia ésser fora de l'ús del vidre es troba en els mosaics, així com també en teulades (Plini, Nat. Hist. 1, 36,64 ) $i$ en els sostres de les cases (Sèneca, Epist. 86, 6). En la decoració de cases i d'esglésies apareix una decoració feta amb vidre durant els primers segles de l'era. Els paviments de vidre són esmentats només una vegada en la literatura (Anthol. Pal. 14, 52).

En l'art mobiliari, les taules foren centre d'atenció de l'aplicació del vidre. Plini parla dels abaci, una mena de taules o de taulers que devien servir per exhibir-hi o posar-hi diversos atuells. Es testimonien també taules fetes amb êlektron, entès com una mescla d'or $i$ vidre, tot $i$ que aquest nom significà un altre material. A Santa Sofia, hi havia una taula feta amb aquesta substància (Zonaras, s. u.).

L'art sumptuari és ric en materials fets de vidre, amb una particularitat, la de la imitació. El vidre és un material molt assequible i mal.leable, la qual cosa possibilitava la imitació de pedres nobles i cares. Es parla, doncs, d'una maragda de vidre (Petroni, Satur. $55,6,10$ ) que Neró utilitzava per descansar la vista, i Plini i Isidor (Orig. 16, 15, 17) fan esment de la diversitat de receptes per imitar les maragdes i de les dificultats per distingir una pedra autèntica d'una feta amb vidre. S'imitaren també el lapislàtzuli, el cristall, la murra, l'òpal, el caboncle, el topaci, el jaspi, el jacint, l'obsidiana, el safir, les perles i l'ònix. Fins aquí, les fonts literàries. Les fonts arqueològiques, però, conservades als museus són una bona prova que el vidre servia també per fer imitacions d'altres moltes gemmes. L'ús d'aquestes imitacions en obres sumptuàries es veu sobretot en els adorns de joieria, especialment en arracades i anells, "souvenirs" per a l'exportació, copes, amulets, i un llarg etcètera.

\section{En objectes de taula $i$ de cuina}

Una altra àrea coberta esplèndidament pel vidre és la de la vaixella i similars. Es tracta, naturalment, del vidre bufat o del fet amb motlle. La terminologia clàssica comprèn vuitanta peces pel cap baix, i certament 
no inclou totes les peces dels museus. En relació, doncs, amb aquests vasos o contenidors petits, cal indicar que el món grec de l'època clàssica coneixia el vidre com a producte forani, i que els romans del segle primer de l'Era el tenien per una cosa nova, i per a ambdós pobles el vidre o els objectes de vidre eren quelcom molt útil, ornamental i car. Per altra banda, les fonts clàssiques no testimonien científicament sobre la manera ni el lloc on el vidre féu acte de presència, llevat d'aquelles fonts que envolten el seu origen en anècdotes $i$ històries que semblen més aviat llegendes. No cal, doncs, que les repetim aquí. Ara bé, un cop introduit el vidre al món romà, les fonts literàries recullen la seva popularitat pel que fa a les formes dels vasos. Sèneca és explícit en escriure: "M'agradaria presentar a Posidoni un vidrier que, amb el seu buf, modela el vidre en moltes formes, les quals apenes podrien ésser fetes per una mà diligent" (Epist. 90, 31). El testimoni d'Ateneu és encara més eloqüent: “Els d'Alexandria, segons que es diu, modelen el vidre en moltes formes diferents de copes, tot imitant la forma dels vasos de terrisa importats d'arreu" $(11,784 \mathrm{c})$. I, al segle $\vee$ d.C., Teodoret de Cirros encara exclamarà: “ ¿Com sap ell modelar, a partir d'aquesta massa, amb foc $i$ amb un potent buf, milers de formes de vasos, i els altres objectes apropiats a tot ús a l'hora de menjar i de beure?" (De Prouidentia, 4, 39).

El costum més documentat sobre la manera d'anomenar els objectes de vidre consisteix a designar-lo precisament amb el nom comú que, a cada època, designà "vidre". Veiem fonts. Petroni fa exclamar a Trimalqui: «Tu m'excusaràs pel que vaig a dir: jo prefereixo els vasos de vidre, almenys no fan olor, i, si no fossin tan fràgils, jo els preferiria als d'or. De moment, però, són barats» (Satur. 50). I, a continuación (51), afegeix: "Hi hagué un artesà que féu una copa de vidre que no es trencava. Fou admès davant del Cèsar (Tiberi) amb el seu regal; a continuació, féu que el Cèsar l'agafés i que la llancés al terra. El Cèsar quedà perplex. Ell, però, recolli la copa del terra, que s'havia abonyegat com un vas de coure, tragué un martell de la seva butxaca $i$, pacientment, arreglà la copa de la manera correcta. Fet això, es pensava obtenir el soli de Júpiter, sobretot quan el Cèsar li preguntà: “¿Algú altre coneix aquesta mena de copes?". Presta atenció, ara. Quan ell hagué dit que no, el Cèsar ordenà que li tallessin el coll, perquè, en el cas que es conegués, tindríem el preu de l'or com el de la terrissa». Plini esmenta també el mateix invent i en la mateixa època, però li lleva tota credibilitat ( $N a t$. Hist. 36, 195). La historieta és recontada per Dió Cassi (s. II d.C.; 57, 21, 7), per Isidor (s. VI-VII; Orig. 16, 16, 6), i fou transplantada a l'època de Richelieu i repetida en altres variades fonts (cf. M. L. Trowbridge, 0 . $c$. 112). Marcial (s. I d.C.), en un bell epigrama (4, 85, 1), diu: “Nosaltres 
bebem amb una copa de vidre; tu, amb una murrina, Pòntic, per què? Deixa que una copa transparent reveli les dues menes de vi».

Cal posar aquí el punt final a aquesta exposició. L'aportació de la Filologia clàssica és evident i notòria, és a dir, no passa desapercebuda. Els estudis, però, per fer apunten encara cap a una investigació del vidre en el seu ús en medicina i en la seva aplicació en moltes circumstàncies de la vida quotidiana, aspectes aquests interessantíssims que constituiran un tema ben complet en estudis posteriors. 
